\title{
La representación de la diversidad social en los materiales didácticos digitales ${ }^{1}$
}

The representation of social diversity in educational multimedia materials

\author{
Laura Rego-Agraso \\ Universidade da Coruña (UDC) \\ laura.rego@udc.es
}

Eva María Barreira Cerqueiras

Universidade de Santiago de Compostela (USC)

evamaria.barreira@usc.es

Raquel Mariño Fernández

Universidade de Santiago de Compostela (USC)

raquel.marino@usc.es

Fecha presentación: 06/02/2018 | Aceptación: 02/05/2018 |Publicación: 22/06/2018

\section{Resumen}

Con la extensión del uso de Materiales Didácticos Digitales (MDD) en la Educación Primaria en España, es pertinente analizar cómo estos representan la diversidad funcional, sexual, cultural, étnico/cultural, etario o de género en nuestra sociedad. Ese es uno de los objetivos del proyecto La escuela de la sociedad digital: análisis y propuestas para la producción y uso de los contenidos digitales educativos, que se está desarrollando en España -concretamente en Galicia, Valencia e Islas Canarias-. La metodología de estudio ha sido mixta -cuantitativa y cualitativa-centrada en el análisis de una muestra de 56 MDD ubicados en plataformas on line institucionales, comerciales y colaborativas procedentes de las comunidades autónomas mencionadas. Entre los resultados más destacados mencionar una mayor tendencia a la visibilización de la mujer -en mayor medida en los MDD presentes en repositorios colaborativos docentes-, aunque continúa la ocultación de determinados grupos analizados en su contenido icónico-textual.

Palabras clave: material didáctico; materiales multimedia; estereotipos; diversidad social; equidad

\section{Resum}

Amb l'extensió de l'ús de Materials Didàctics Digitals (MDD) a Espanya, és pertinent analitzar com aquests recursos representen la diversitat funcional, sexual, cultural, ètnic / cultural, etari o de gènere en la nostra societat. Aquest és un dels objectius del projecte L'escola de la societat digital: anàlisi i propostes per a la producció $i$ ús de continguts educatius digitals, que s'està desenvolupant a Espanya -concretament a Galícia, València i Illes Canàries-. La metodologia d'estudi ha estat mixta -quantitativa i qualitativa- centrada en l'anàlisi de una mostra de 56 MDD ubicats en plataformes on line institucionals, comercials i collaboraries procedents de les comunitats autònomes esmentades. Entre els resultats més destacats esmentar una major tendència a la visibilització de la dona -en major mesura en els MDD presents en repositoris collaboratius docents-, tot i que continua l'ocultació de determinats grups analitzats en el seu contingut icònic-textual.

Paraules clau: material didàctic; materials multimèdia; estereotips; diversitat social; equitat

\section{Abstract}

With the spreading of multimedia educative materials use in Primary Education in Spain, it seems pertinent to analyse how these resources represent the diversity of gender, ability, sexual orientation, cultural/ethnic diversity or age variations in our society. This is one of the aims of the project The school of the digital society: analysis and proposals for the production and use of educational digital contents, which is being developed nowadays in Spain, specifically in

\footnotetext{
${ }^{1}$ Este artículo es parte del proyecto de investigación La escuela de la sociedad digital: análisis y propuestas para la producción y uso de los contenidos digitales educativos (EDU2015-64593-R) financiado por Programa Estatal I+D+I Retos Sociedad Convocatoria 2015.
} 
Rego-Agraso, Laura; Barreira Cerqueiras, Eva María y Mariño Fernández, Raquel (2018) “La representación de la diversidad social en los materiales didácticos digitales". @tic revista d'innovació educativa, 20, 63-71.

Galicia, Valencia and the Canary Islands. Therefore, a methodology of mixed (quantitative and qualitative) study has been applied, focused on the analysis of a sample of 56 multimedia materials, located in institutional commercial and online collaboration platforms of the aforementioned autonomous communities. Among the most outstanding results, it is worth mentioning a greater tendency towards the visibility of women -especially in that resources present in collaborative teaching repositories-, although it is continued the concealment of certain groups analyzed in its iconictextual content.

Key Words: educational resource; multimedia materials; textbook bias; stereotype; cultural pluralism; equity

\section{Introducción}

Las Tecnologías de la Información y la Comunicación (de aquí en adelante, TIC) se han convertido en realidades omnipresentes en las sociedades industrializadas, penetrando en multitud de espacios y sectores productivos, lo que ha alterado substancialmente los procesos de elaboración, distribución y consumo de información, conocimiento y cultura (Area Moreira, 2016). Tanto las industrias culturales tradicionales como los materiales didácticos asociados a ellas, -como es el caso del libro de texto en papel- han sufrido considerables transformaciones asociadas a esta nueva realidad, dado que actualmente comienzan a compartir su antiguo monopolio (Ídem) en las escuelas con recursos digitales diversos, basados en las TIC y denominados Materiales Didácticos Digitales (de aquí en adelante, MDD). En base a ello, cabe preguntarse cómo estos nuevos recursos digitales representan la diversidad existente en nuestra sociedad y hasta qué punto, ejercen como elementos reproductores de la cultura hegemónica por un lado, o contribuyen a la invisibilización de determinados colectivos considerados no normativos y que interpelan a la diversidad existente en nuestra sociedad. Aludimos por ejemplo, no sólo a la representación de las mujeres sino a la de personas diversas desde el punto de vista funcional, sexual, cultural, étnico o etario que se realiza en estos nuevos materiales didácticos con base en la red y las TIC.

A continuación se propone el estado de la cuestión en torno a la representación de la diversidad en los materiales didácticos siguiendo algunas investigaciones nacionales e internacionales sobre el particular para, posteriormente, explicar la metodología de investigación seguida en el estudio que aquí se presenta, los resultados alcanzados y una serie de conclusiones derivadas directamente de lo anterior.

\section{La representación de la diversidad en los materiales didácticos: estado de la cuestión}

Los libros de texto como material didáctico han sido y siguen siendo elementos que ocupan, en gran parte de las aulas, la centralidad del proceso educativo. Pueden ser considerados de facto como dispositivos al servicio de la transmisión cultural, discursos y lecturas construidas y difundidas de forma cuasi hegemónica mediante el sistema educativo. Para Tiana (2000, p.102 cit. en Vaíllo, 2016) los libros de texto en su multidimensionalidad pueden ser conceptualizados como "productos de consumo, soportes de conocimientos, fuentes de ideología y normas culturales e instrumentos que sirven a fines pedagógicos".

En la actualidad, este espacio de centralidad y significados socioeducativos múltiples tradicionalmente ocupado por los libros de texto, comienza a ser desplazado y sustituido por otros materiales didácticos que tienen en las TIC su suporte esencial. Se trata de los MDD, los cuales en su configuración no dejan de reproducir y ser utilizados, según recientes aportaciones (Cepeda et al., 2017), bajo estructuras didácticas y planteamientos pedagógicos poco diferenciados de los propuestos por el tradicional libro de texto en formato papel, o en todo caso no aplicando todo el potencial de las TIC (Area et al., 2010). Esta misma situación de continuismo metodológico también se ha detectado en relación a las plataformas educativas digitales comerciales (Castro-Rodríguez et al., 2017).

Ante esta realidad, sería apropiado partir de la hipótesis de que la construcción discursiva de la realidad social presente los MDD, también va a reproducir otras cuestiones igualmente presentes en los materiales en formato impreso. Se trata de procesos de invisibilización o discriminaciones asociados a distintos colectivos o grupos específicos y vinculados con el uso del lenguaje y la reproducción de estereotipos.

En este sentido, diversas investigaciones sobre materiales didácticos a nivel nacional e internacional, ponen de manifiesto la omisión de las mujeres, su invisibilización (Cabrera y Martínez-Bello, 2014; LópezNavajas, 2014 o Biemmi, 2015) y también la difusión de estereotipos asociados al género en materiales educativos de diversa índole (González, 2005; Mineshima, 2008; Hall, 2014 o Gómez y Tenza, 2015, entre otras). Sin embargo, también existen otras investigaciones recientes (Sleeter y Grant, 2011; MoyaMata et al., 2013; Menescardi et al., 2017), que presentan la existencia de ciertos avances en este sentido, destacando que en estos estudios se percibe un descenso o inexistencia de estereotipos asociados al género en los libros de texto orientados a la infancia, siendo la visibilización de hombres y mujeres más equitativa.

El género no deja de ser un constructo socialmente configurado, donde la interacción humana y su interpretación parece más relevante que el propio determinismo biológico (Berkowitz et al., 2010 cit. en Lee, 2014). Se trata de una construcción social mediatizada por la influencia de familia, escuela, iguales o medios de comunicación, entre otros agentes. De igual modo, la concepción de la diversidad en sus múltiples manifestaciones- etaria, sexual, étnica, funcional o cultural-también se construye en el imaginario colectivo a través, no sólo de las vivencias propias, sino de las representaciones que otros realizan sobre la realidad social, bien sea en los materiales escolares -MDD, entre ellos- o mediante cualquier otro dispositivo de comunicación social.

Sin embargo, los estudios que analizan las representaciones de la diversidad en general en los materiales didácticos, particularmente en los digitales, son cuantitativamente inferiores a los que profundizan específicamente sobre la presencia y visibilización de las mujeres. Con todo, existen investigaciones que analizan la presentación del cuerpo humano en los libros de texto (Martínez-Bello, 2013 o Martínez-Bello y Martínez-Bello, 2016) o la diversidad étnica y de clase social (Puentes y 
Rego-Agraso, Laura; Barreira Cerqueiras, Eva María y Mariño Fernández, Raquel (2018) "La representación de la diversidad social en los materiales didácticos digitales". @tic revista d'innovació educativa, 20, 63-71.

Gougherty, 2011), que ponen de manifiesto que las imágenes de estos materiales son muy relevantes en las primeras etapas escolares, actuando "como elementos motivadores y reforzadores de valores e ideas" (Selander, 1990, cit. en Martínez-Bello, 2013). Precisamente según este autor (Ibídem, p. 3) los materiales que omiten o presentan estereotipos asociados a género, etnia, edad o funcionalidad "transmiten y refuerzan ideologías dominantes respecto de la construcción del concepto del cuerpo, así como estereotipos [...] que generan estándares de masculinidad y feminidad, superioridad o capacidad física".

De forma más concreta, con respecto a las investigaciones sobre la representación de la diversidad funcional en los materiales didácticos cabe señalar que también son relativamente pocas y en su mayoría se vinculan con la disciplina de Educación Física (TáboasPais y Rey-Cao, 2012; González-Palomares y Rey-Cao, 2013 o Moya-Mata et al., 2017). En todas ellas los resultados muestran que existe una desproporción clara entre la presentación de personas con y sin diversidad funcional en dichos materiales. Las personas con diversidad funcional son prácticamente excluidas en las imágenes de los materiales didácticos analizados, siendo de hecho, la mujer con discapacidad casi invisible y cuando aparece, lo hace representada de forma más frecuente como blanca, joven y en silla de ruedas (MoyaMata et al., 2017) Además, la actividad deportiva que aparece realizando tiene lugar en un ámbito competitivo y de alto nivel (Ídem), lo que contribuye a presentar a las personas con diversidad funcional como superhéroes o superheroínas. No se muestra por lo tanto, a estas personas realizando actividades cotidianas semejantes a las que realizan aquellas consideradas sin discapacidad o compartiendo espacios con ellas en la cotidianeidad, lo que contribuiría sin duda a la normalización de la diversidad en las representaciones que manejan los niños y niñas a lo largo de su escolaridad. Otra investigación centrada en la literatura infantil y juvenil empleada en Reino Unido en las escuelas, pone de manifiesto parcialmente esta misma situación al analizar un total de 100 publicaciones (Beckett et al., 2010). Decimos parcialmente, porque, al tiempo que se destaca que existen publicaciones centradas en favorecer una educación inclusiva y, por lo tanto, una visión incluyente de la diversidad, persisten muchas otras que representan la diversidad funcional bajo uno de los siguientes enfoques (Ídem): como una tragedia individual; como una curiosidad o rareza cuasi mágica; como una lección para todos/as -especialmente en la literatura religiosa, las personas con diversidad existen por el bien espiritual o moral de otras personas, para ponerlas a prueba o presentan dificultades que se pueden superar con la voluntad de dios-o como una situación temporal que tiene un final feliz en muchos casos, no realista. También se detectan - en la mayor parte de las publicaciones analizadas en este estudio-, usos no adecuados del lenguaje que contribuyen a estereotipar o invisibilizar a las personas con diversidad. En relación con la diversidad étnica, otros estudios muestran que la representación de los diferentes grupos en libros de texto y materiales didácticos es escasa y normalmente asociada con el deporte de competición (González-Palomares y Rey-Cao, 2013). Martínez-Bello (2013) coincide con este diagnóstico cuando muestra en su estudio sobre libros de texto de editoriales españolas que la representación del origen fenotípico europeo es el que cuenta con una mayor presencia, mientras que representaciones como negra, mestiza o asiática son minoritarias en dichas publicaciones. En otros países europeos esta situación también se ha constatado (Weninger y Williams, 2005) y en los países latinoamericanos como Colombia (Soler-Castillo, 2008, p. 659) se une a esta realidad el hecho de que por ejemplo "Ios afrodescendientes casi siempre aparecen ligados a [...] la esclavitud", omitiendo su aportación a la cultura o a la vida social y económica del país en la actualidad.

En cuanto a la diversidad etaria, son varios los estudios (González-Palomares y Rey-Cao, 2013 o Rey-Cao, Táboas-Pais y Canales, 2013) que ponen de manifiesto que las personas mayores están ausentes en los materiales didácticos -también en los digitales (Zapico, 2015) - Carecen en muchos casos de representación alguna y por lo tanto, se perpetúa su ocultación en estas publicaciones. En otra investigación que analiza 1.774 imágenes de 5 colecciones de libros de texto de la asignatura de inglés (Menescardi et al., 2017), destaca una sobrerrepresentación de gente joven en dichas imágenes, lo que parece resultar "más atractivo que el uso de imágenes de personas de la tercera edad" (Ibídem, p. 70), asociando a este colectivo con el sufrimiento, la dependencia o el dolor. Según Candas y García (2006, cit. en Menescardi et al., 2017) esto contribuye a que las personas jóvenes perciban a los mayores como personas molestas o que no se pueden valer por sí mismas.

En relación a la diversidad afectivo-sexual, los estudios realizados sobre su representación en los materiales didácticos son pocos pero coincidentes. Para Torres (2008), los sistemas educativos que asumen un modelo de sociedad mono-cultural tienen a silenciar y ocultar otras realidades no hegemónicas, tal es el caso de las culturas asociadas a la diversidad sexual. La representación de personas lesbianas, gais, transexuales, bisexuales o intersexuales (de aquí en adelante, LGTBI) en materiales didácticos y libros de texto ha sido analizada también en otras latitudes: EEUU (Macgillivray y Jennings, 2008) y Sudáfrica (Potgieter y Reygan, 2012) por ejemplo. En el caso estadounidense, tras el análisis realizado -que incluye aspectos como la representación de procesos de discriminación o acoso contra el colectivo LGTBI; la familia, padres o tutores/as del alumnado LGTBI; la presentación de las identidades LGTBI o las estrategias curriculares para incrementar la seguridad y el apoyo al colectivo-, se destaca que el colectivo está presente, lo cual se valora como algo positivo. Sin embargo, se indica que su representación en relación al conjunto del discurso puede reforzar la pervivencia de estereotipos negativos sobre el colectivo y, en consecuencia, su discriminación directa o indirecta. Por lo que respecta al estudio que analiza materiales didácticos en el contexto Sudafricano, se indica que la presencia y representación del colectivo LGTBI es desigual en dichos materiales. Por ejemplo, la identidad gay masculina aparece en algunas ocasiones representada, mientras que la identidad lesbiana y bisexual aparece rara vez y las personas transgénero e intersexuales en ningún caso (Potgieter y Reygan, 2012). La invisibilización y escasez de materiales adecuados en relación al tratamiento igualitario y no discriminatorio del colectivo parece ser uno de los elementos clave en relación a los materiales didácticos, también en España, tal como viene analizando la Federación Estatal De Lesbianas, Gais, Transexuales y Bisexuales (FELGT) en 
Rego-Agraso, Laura; Barreira Cerqueiras, Eva María y Mariño Fernández, Raquel (2018) "La representación de la diversidad social en los materiales didácticos digitales". @tic revista d'innovació educativa, 20, 63-71.

relación al sistema educativo (Moreno, 2006 o Tofiño, 2006). Sin embargo, existen otro tipo de materiales asociados a la inclusión y respeto por la diversidad que algunas investigaciones destacan como positivos aunque en algunos casos mejorables- a la hora de visibilizar al colectivo y permitir la auto-identificación del alumnado con los personajes y situaciones presentadas. Es el caso del cómic (Soler-Quílez, 2015) y del álbum ilustrado (Soler-Quílez, 2016).

\section{Metodología del estudio}

La investigación que aquí se presenta se contextualiza bajo la pretensión global de explorar los fenómenos y procesos educativos que acompañan al cambio del modelo de distribución, acceso y uso de los materiales didácticos en el contexto escolar. En este sentido, es de especial interés el impacto e influencia que estos nuevos materiales digitales pueden ejercer sobre los agentes educativos que los usan y sobre las prácticas de enseñanza y aprendizaje desarrolladas en los centros escolares.

\subsection{Objetivos}

De este modo, uno de los objetivos generales del proyecto en el que se ubica el estudio que aquí se presenta "La escuela de la sociedad digital: análisis y propuestas para la producción y uso de los contenidos digitales educativos" (EDU2015-64593-R) es "analizar las características pedagógicas y tecnológicas de una muestra de repositorios y plataformas de contenidos educativos digitales, así como de una parte de los MDD alojados en dichos repositorios y plataformas". Teniendo esto en cuenta, los objetivos específicos a alcanzar tienen que ver con:

1. Diseñar y validar un instrumento de análisis de contenidos educativos digitales.

2. Aplicar dicho instrumento de análisis a una muestra de contenidos digitales seleccionados desde las comunidades autónomas implicadas en el estudio (Galicia, Valencia e Islas Canarias) y extraídos de los repositorios y plataformas (institucionales, comerciales y de otra índole) previamente seleccionadas.

3. Realizar un análisis comparativo entre los distintos materiales o plataformas digitales analizadas.

\subsection{Muestra}

Tomando como guía los objetivos mencionados, desde las tres comunidades autónomas participantes se procedió a seleccionar una serie de plataformas, repositorios 0 portales educativos de carácter institucional, comercial o de otra índole y, a su vez, dentro de cada uno de ellos, Ios MDD a analizar. Con respecto a la selección de las plataformas, repositorios o portales educativos, se tomaron en consideración los siguientes criterios de selección de la muestra:

- Debía tratarse de una plataforma o portal educativo on line dirigido al alumnado $y$ profesorado de Educación Primaria en cada una de las comunidades autónomas participantes en el estudio (Galicia, Valencia e Islas Canarias).

- Debía contener MDD dirigidos a los cursos $5^{\circ}$ y $6^{\circ}$ de Educación Primaria disponibles para su uso o bien, en formato restringido ${ }^{2}$ o bien, en acceso abierto.

- Ser promovidas por instituciones educativas públicas (institucionales), por empresas o editoriales educativas (comerciales) o por otros colectivos (de otra índole). En cuanto a la selección de los portales institucionales, se decidió analizar todos los existentes en las 3 comunidades autónomas participantes -Abalar en Galicia; Mestre a casa y chaval.es en Valencia ${ }^{3}$ y Ecoescuela en Islas Canarias-. En lo que respecta a la selección de los portales comerciales, de todas las opciones existentes, se han seleccionada aquellos cuyas empresas han dado su apoyo expreso al estudio en la fase de diseño y elaboración, así como aquellos que, por su amplia difusión entre la población escolar, se han considerado relevantes en cada comunidad autónoma. La selección de los portales diseñados y elaborados por otros colectivos diferentes a los anteriormente mencionados, se ha llevado a cabo en función de los que se han localizado en cada comunidad autónoma que cumplieran con los dos criterios anteriormente señalados.

Se han seleccionado finalmente para el análisis, 23 plataformas 0 portales educativos que contienen diversos MDD y que proceden de las 3 comunidades autónomas objeto de estudio: 7 portales de Galicia; 8 de Valencia y 8 de Islas Canarias. Una vez analizados dichos portales educativos, se procedió a identificar y seleccionar los MDD que serían también objeto de análisis. Dichos MDD fueron escogidos en base a los criterios que se presentan a continuación, los cuales fueron aplicados en cada una de las comunidades autónomas participantes. Se debían elegir entonces para el análisis:

- De 2 a 5 MDD procedentes de cada una de plataformas institucionales en cada comunidad autónoma (en caso de existir).

- Un mínimo de 3 MDD procedentes de plataformas comerciales relevantes en cada comunidad autónoma y con presencia en el sistema escolar.

- Un mínimo de 2 MDD procedentes de otros tipos de plataformas (minoritarias) en cada comunidad autónoma.

- $\quad$ Debían ser MDD dirigidos a los niveles de $5^{\circ}$ y $6^{\circ}$ de Educación Primaria.

- Debían ser MDD orientados a las asignaturas de Matemáticas, Lengua Castellana/Lenguas oficiales, Música y Ciencias Sociales 4 .

- Debían permitir el análisis en todas las dimensiones de la Guía para el análisis de materiales didácticos digitales.

\footnotetext{
2 En el caso de contar con acceso restringido, se solicitó a cada una de las entidades promotoras del portal o plataforma autorización expresa para que el equipo investigador pudiese acceder libremente a su contenido y aplicar el análisis.

3 En el caso de Valencia también existe otra plataforma educativa institucional a cargo del Centro de Formación, Innovación y Recursos Educativos (CEFIRE) de Elda, pero no ha sido analizado al considerar que en este repositorio predominan los documentos de carácter impreso y los MDD son escasos.

${ }_{4}^{4}$ Pero no por ello se restringió la posible selección de MDD orientados al trabajo de contenidos transversales del currículo.
} 
Rego-Agraso, Laura; Barreira Cerqueiras, Eva María y Mariño Fernández, Raquel (2018) "La representación de la diversidad social en los materiales didácticos digitales". @tic revista d'innovació educativa, 20, 63-71.

Cumpliendo con estos criterios, se ha aplicado esta Guía a un total de 13 materiales procedentes de la comunidad gallega, otros 13 procedentes a la comunidad valenciana y 30 cuyo origen se sitúa en las Islas Canarias. La muestra final resultante está compuesta entonces, por un total de 56 MDD distribuidos tal como se presenta en la Tabla 1.

\begin{tabular}{|c|c|c|c|c|c|}
\hline \multicolumn{2}{|c|}{ GALICIA } & \multicolumn{2}{|c|}{ VALENCIA } & \multicolumn{2}{|c|}{ CANARIAS } \\
\hline Plataforma & $\begin{array}{c}\text { No MDD } \\
\text { analizados }\end{array}$ & Plataforma & $\begin{array}{c}N^{\circ} \mathrm{MDD} \\
\text { analizados }\end{array}$ & Plataforma & 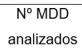 \\
\hline $\begin{array}{c}\text { ABALAR } \\
\text { (institucional) }\end{array}$ & 3 & $\begin{array}{c}\text { MESTRE A CASA } \\
\text { (institucional) }\end{array}$ & 5 & $\begin{array}{l}\text { ECOESCUELA } \\
\text { (institucional) }\end{array}$ & 4 \\
\hline $\begin{array}{l}\text { SANTILLANA } \\
\text { (comercial) }\end{array}$ & 2 & $\begin{array}{l}\text { CHAVAL.ES } \\
\text { (institucional) }\end{array}$ & 1 & $\begin{array}{l}\text { PROCOMÚN } \\
\text { (institucional) }\end{array}$ & 3 \\
\hline $\begin{array}{l}\text { EDICIÓNS } \\
\text { XERAIS DE } \\
\text { GALICIA } \\
\text { (comercial) }\end{array}$ & 2 & $\begin{array}{l}\text { BROMERA } \\
\text { (comercial) }\end{array}$ & 2 & $\begin{array}{l}\text { SANTILLANA } \\
\text { (comercial) }\end{array}$ & 4 \\
\hline $\begin{array}{l}\text { GALINOVA } \\
\text { (comercial) }\end{array}$ & 2 & $\begin{array}{l}\text { ITBOOK } \\
\text { (comercial) }\end{array}$ & 1 & $\begin{array}{c}\text { EDEBÉ } \\
\text { (comercial) }\end{array}$ & 4 \\
\hline $\begin{array}{c}\text { ANAYA } \\
\text { EDUCACIÓN } \\
\text { (comercial) }\end{array}$ & 2 & $\begin{array}{l}\text { TABARCA } \\
\text { (comercial) }\end{array}$ & 1 & $\begin{array}{l}\text { DIGITAL - } \\
\text { TEXT } \\
\text { (comercial) }\end{array}$ & 4 \\
\hline $\begin{array}{c}\text { AIOVAIEDUCA } \\
\text { CIÓN } \\
\text { (otras) }\end{array}$ & 1 & $\begin{array}{l}\text { VORAMAR } \\
\text { (comercial) }\end{array}$ & 1 & $\begin{array}{l}X-\text { TEND } \\
\text { (comercial) }\end{array}$ & 4 \\
\hline EDUCABANA & & $\begin{array}{l}\text { EDUCAIXA } \\
\text { (otras) }\end{array}$ & 1 & $\begin{array}{l}\text { InEveryCrea } \\
\text { (otras) }\end{array}$ & 3 \\
\hline (otras) & 1 & $\begin{array}{l}\text { UNENTRETANTS } \\
\text { (otras) }\end{array}$ & 1 & $\begin{array}{l}\text { Tiching } \\
\text { (otras) }\end{array}$ & 4 \\
\hline TOTAL & 13 & TOTAL & 13 & TOTAL & 30 \\
\hline
\end{tabular}

Tabla 1. Materiales analizados según plataforma de alojamiento y comunidad autónoma. Fuente: Elaboración propia a partir de Area Moreira (2016)

\subsection{Instrumento}

De manera más específica, en este artículo se pretende analizar desde la perspectiva de la diferencia y la diversidad, una muestra de MDD que las plataformas y repositorios educativos antes mencionados contienen en las 3 autonomías participantes en el estudio. Para conseguir esta meta, se ha utilizado una metodología mixta - cualitativa y cuantitativa- reflejada inicialmente en el uso del instrumento Guía para el análisis de materiales didácticos digitales -diseñado ad hoc, aplicado a una submuestra y validado por jueces expertos a nivel internacional-, el cual recoge una serie de ítems vinculados con las dimensiones: tecnológica, de diseño, pedagógica, de contenido y de evaluación. Dicho instrumento cuenta con ítems de respuesta abiertos -en su mayoría- y también cerrados. Es la dimensión de contenido la que nos interesa, pues en ella se recogen ítems que nos proporcionan datos valiosos sobre la manera de representar la diversidad en cualquiera de sus vertientes dentro de los MDD. Más concretamente, nos centramos en analizar el ítem: “¿El contenido icónico y textual refleja la diversidad funcional, de género, sexual, cultural, etaria (de distintas edades)?". Por consiguiente, la variable de referencia en la que hemos centrado nuestra atención es la siguiente: representación de la diversidad social -género, funcional, etaria, sexual o étnica/cultural- en los materiales digitales analizados.

\subsection{Procedimiento}

El procedimiento desarrollado se ha estructurado de forma que se dé respuesta a los objetivos formulados y, en consecuencia, ha atendido a las siguientes fases:

1) Fase de elaboración del instrumento de análisis plataformas, portales y materiales educativos-:
Guía de análisis de Plataformas y Guía para el análisis de materiales didácticos digitales.

2) Fase de validación: aplicación de los instrumentos a una submuestra de repositorios y materiales por parte del equipo investigador; revisión del instrumento por parte de expertos/as internacionales e incorporación de sugerencias y modificaciones al mismo.

3) Fase de análisis de las plataformas comerciales, portales institucionales y colaborativos por parte del equipo investigador y mediante un instrumento específico también diseñado ad hoc.

4) Fase de análisis de los MDD procedentes de las plataformas y portales educativos por parte del equipo investigador: Esta fase y la anterior se han desarrollado de forma simultánea por parte de los 3 grupos de trabajo de las comunidades autónomas participantes.

5) Elaboración de los informes correspondientes, por parte de los 3 grupos de investigación implicados con los resultados más destacados.

\subsection{Análisis de datos}

El análisis se ha realizado tomando en consideración el tipo de plataforma/portal educativo que ubica a los MDD analizados, de ahí que los resultados serán presentados atendiendo a dicha la tipología como elemento categorizador -según su carácter institucional, comercial o de otra índole-. Empleando estas categorías se tratará de analizar en qué medida existe o no esa representación de la diversidad social representaciones del género, de la identidad y orientación sexual (LGTBI), de la diversidad funcional, de la diversidad etaria y étnico/cultural-y cómo se muestra en los MDD seleccionados.

\section{Resultados}

Los MDD procedentes de portales institucionales se caracterizan por tener un diseño cerrado y exclusivamente centrado en la temática y contenidos curriculares específicos. Ello impide una fácil adaptación por parte del profesor/a, del MDD al contexto próximo de los destinatarios/as, a sus intereses particulares 0 al alumnado con diversidad funcional. Por ejemplificar esta cuestión, podemos mencionar el caso de la plataforma institucional gallega Abalar, cuyos MDD examinados no permiten, curiosamente, una adaptación lingüística a cualquiera de los idiomas propios de la comunidad autónoma de Galicia. Por su parte, en la comunidad valenciana, los recursos institucionales tampoco están contemplados en la lengua propia o, en el caso de hacerlo, adolecen de errores lingüísticos en su traducción que merman la calidad de dichos materiales. Así mismo, la diversidad social desde el punto de vista de la consideración de distintas dimensiones -sexual, de género, étnica/cultural, etaria o funcional- no está presente en prácticamente la totalidad de los materiales analizados. Esta situación se ha constatado al observar el contenido icónico y las representaciones de los sujetos que aparecen en los mismos. Son escasos los MDD que hagan alusión o que presenten -aunque sea de forma esporádica- imágenes que lleven el imaginario del destinatario/a a una representación realista de la diversidad en todas las dimensiones propuestas. La mayor parte de las representaciones icónicas y textuales se corresponden con lo que hemos asociado en el apartado anterior a lo hegemónico: niños/hombres de 
origen fenotípico europeo, sin diversidad funcional, jóvenes y heterosexuales.

En el caso de las plataformas comerciales se dan situaciones de corte similar. Aunque se trata de recursos mayoritariamente cerrados en su estructura y configuración -sobre todo el libro de texto en formato digital-, muestran la posibilidad de ampliar información en algunos contenidos o temáticas a través de actividades fuera del entorno virtual o con enlaces a otros recursos en la red. Por ello, podemos entender que la selección y adaptación permitida en relación a las decisiones docentes y adaptación al alumnado, es mucho más abierta que en el caso anterior. Sin embargo, Ios materiales y recursos analizados siguen adoleciendo de un escaso tratamiento de la diversidad en las dimensiones analizadas según lo que establecen los investigadores/as que aplicaron la Guía para el análisis en las tres comunidades

Una cuestión bastante significativa es lo que acontece en dos de las comunidades autónomas participantes en este proyecto, ambas con identidad cultural y lengua propia. En ellas, la mayor parte de los MDD analizados vinculados con plataformas comerciales no reflejan las diferencias culturales y/o lingüísticas, tanto de carácter estatal como autonómico. En el caso de Galicia por ejemplo, aunque los materiales comerciales se relacionan superficialmente con el entorno social y cultural de esta autonomía, únicamente se ha encontrado un MDD plenamente contextualizado en la realidad gallega, en su entorno sociocultural y que utilice su lengua propia como vehicular.

Igualmente se han detectado leves referencias a la existencia de la diversidad de género desde la perspectiva planteada o representaciones e imágenes que así lo sugieren. Sin embargo, en otros MDD también asociados a estas plataformas comerciales, se ha detectado la persistencia de determinados estereotipos o concepciones tradicionalistas en torno a cuestiones como, por ejemplo el rol de la mujer o la persistencia de un único modelo familiar basado en una pareja heterosexual, con una clara vinculación a la función reproductiva.

Con todo, en el caso de la comunidad valenciana los MDD analizados vinculados a plataformas comerciales presentan la diversidad en muchas de sus dimensiones, desde un punto de vista positivo, de conocimiento y de entendimiento de las diferencias. Entre ellas, es posible destacar los dos MDD alojados en la plataforma Bromera, los cuales sí plantean el tratamiento de la diversidad desde la perspectiva textual e icónica. Las imágenes, ilustraciones y texto reflejan la existencia de diversidad, especialmente sexual y cultural, al mostrar a niños y niñas realizando actividades no estereotipadas. Salvo estas excepciones y a pesar de que la mayor parte del contenido icónico de los materiales comerciales de carácter digital presenta a niños y niñas con edades similares al alumnado destinatario, sus características son monocordes, en una clara representación de infantes con rasgos propios de personas de origen fenotípico europeo casi en exclusividad.

En cuanto a las restantes plataformas que no se enmarcan en las categorías anteriores, podemos constatar que en ellas se ubican MDD también en su mayoría cerrados, con temáticas o contenidos muy concretos y vinculados directamente con cada una de las áreas curriculares. Se especializan por tanto, en temas muy delimitados que ayudan a la adquisición de conocimientos específicos, pero que pueden contener carencias a ojos de los investigadores/as en relación a la calidad pedagógica de la propuesta en su conjunto. Sin embargo, al centrarse en áreas de conocimiento concretas y haber sido desarrollados en un contexto territorial preciso, se observa un mejor ajuste al entorno del alumnado al que va dirigido. Por ejemplo, aquellos materiales vinculados con el área de ciencias naturales permiten un tratamiento de especies animales y vegetales propias del espacio natural inmediato de los destinatarios/as. 0 al tratarse de repositorios colaborativos entre la comunidad docente, se integran y se difunden MDD diseñados por el propio profesorado derivados de experiencias desarrolladas en el contexto escolar próximo del alumnado destinatario.

En este tipo de portales de índole colaborativo, se observa así mismo, una representación de la diversidad más amplia que aquella que podemos encontrar en las plataformas institucionales o comerciales, especialmente en cuanto al sexo de los personajes protagonistas. Las representaciones icónicas referidas a individuos en estos materiales suelen ser figuras tanto masculinas como femeninas - niños y niñas con edades similares a los destinatarios/as $u$ hombres y mujeres llevando a cabo determinadas tareas-. Como ejemplo de esta situación podemos aludir a uno de los MDD analizados en la comunidad canaria y alojado en la plataforma Tiching -vinculado con las Ciencias Naturales-, en el cual aparece la representación de una científica mirando por un microscopio o un hombre cerca de un estanque. De este modo, se percibe un interés por eliminar determinados estereotipos y favorecer una visión de la mujer como científica o investigadora, más allá de los roles tradicionalmente asociados a su género. Sin embargo, en relación a la representación de otros colectivos, se detecta que los personajes son en su amplia mayoría personas de origen fenotípico europeo, manteniendo así, una perspectiva étnico-cultural poco diversa. Tampoco se detectan representaciones diferentes de la identidad y orientación sexual, de la diversidad funcional o etaria. La amplia mayoría de los protagonistas de las acciones son niños/as o jóvenes de edades semejantes, sin discapacidad y vinculados a familias heterosexuales. A tenor de lo expuesto, es difícil que los destinatarios/as de estos recursos puedan configurar a partir de ellos, una visión clara de la presencia de diversidad en la sociedad y por lo tanto, se contribuye a un cierto etnocentrismo y se invisibiliza a colectivos que forman parte activa de la misma, pero que se ocultan y por lo tanto, se conceptualizan como no normativos.

\section{Discusión y conclusiones}

La influencia que ejercen los materiales didácticos en las vivencias escolares y los aprendizajes que desarrolla la infancia a través, tanto del lenguaje audiovisual como del discurso elaborado, es de vital importancia y en no pocas ocasiones permanece oculto (García Perales, 2012). El análisis realizado en esta investigación pone de manifiesto como estos materiales digitales pueden convertirse de facto en currículo educativo (Macgillivray y Jennings, 2008) y como transmiten mensajes al alumnado acerca de la realidad, el poder y las jerarquías sociales en función de ciertas marcas de relevancia asociadas a colectivos que se ubican al margen de lo considerado hegemónico.

Las representaciones de los colectivos que se han analizado en los MDD seleccionados - personas con 
Rego-Agraso, Laura; Barreira Cerqueiras, Eva María y Mariño Fernández, Raquel (2018) "La representación de la diversidad social en los materiales didácticos digitales". @tic revista d'innovació educativa, 20, 63-71.

diversidad funcional, mujeres, colectivo LGTBI y personas diversas desde el punto de vista étnico/cultural y etarioresponden a grupos tradicionalmente ausentes o estereotipados dentro de los materiales didácticos impresos (López-Navajas, 2014; Puentes y Gougherty, 2011; González-Palomares y Rey-Cao, 2013; MartínezBello, 2013; Zapico, 2015), lo que parece trasladarse también, al menos parcialmente, a los MDD. De hecho, dentro de los MDD analizados, podemos destacar que los ubicados tanto en plataformas o portales educativos institucionales como en aquellas comerciales, siguen ocultando a la mayor parte de los colectivos analizados en su contenido icónico-textual. Con todo, merece la pena indicar que, coincidiendo con algunos estudios (Moya-Mata et al., 2013 o Menescardi et al., 2017), en nuestra investigación también se detecta cierta tendencia a una mayor visibilización de la mujer en los MDD, pero del mismo modo es cierto que este tipo de diversidad se percibe en mucha mayor medida en los MDD presentes en repositorios colaborativos -no comerciales y no institucionales- diseñados y compartidos por el propio profesorado. Estos MDD suelen ser también los que cuentan con un carácter en mayor medida editable y, por lo tanto, adaptable a las distintas características del alumnado, su contexto y a la aplicación de metodologías de aula diversas.

Por ello, entendemos que podría resultar positivo, tal como indican Menescardi et al. (2017), que el profesorado sea capaz de reconocer en los MDD las distintas representaciones de la diversidad e inclinarse por elegir para su labor diaria, materiales y recursos que la muestren claramente y que favorezcan la igualdad de oportunidades del alumnado, independientemente de sus circunstancias o condiciones vitales. De igual modo, en caso de no contar con un material acorde a lo esperado, el profesorado parece estar en condiciones de diseñar y desarrollar su propio material. De hecho, Vaíllo (2016, p. 108) propone que el profesorado dé el salto desde la evaluación hacia la producción, en este caso de MDD. Sin embargo, de forma complementaria también se echa de menos -y por ello sería interesante favorecer su producción-, la existencia de guías de análisis de los MDD centradas en verificar la representación de una sociedad diversa y equitativa en dichos recursos y que puedan ser, a su vez, de utilidad para editoriales o instituciones que tienen como misión el diseño de MDD. En síntesis, la ocultación en la mayor parte de los símbolos icónicos y textuales de personas con diversidad funcional, personas mayores, colectivo LGTBI o personas diversas desde el punto de vista étnico y cultural parece ser lo más frecuente en los MDD analizados. Cabe mencionar la tendencia al monolingüismo como otro factor clave en relación al tratamiento de la diversidad, aun cuando dichos recursos están dirigidos a alumnado de dos comunidades autónomas con lengua propia. Paralelamente cabe destacar también la baja o nula representación de la diversidad étnico/cultural en los MDD procedentes de la comunidad canaria, máxime considerando que se trata de una de las autonomías más multiculturales del estado, sobre todo a nivel escolar, lo que se refleja en los centros educativos canarios mediante el desarrollo de Programas de Pluralidad Cultural (Consejo Escolar de Canarias, 2001). Sería necesario por lo tanto, incrementar claramente la diversidad en las representaciones icónico-textuales y emplear en los MDD personajes de distintas etnias, nacionalidades $u$ orígenes, acercando así dichos materiales a la realidad vivenciada y permitiendo una mayor identificación del alumnado con los personajes representados como aprendices o protagonistas de las acciones.

Sigue siendo necesario por lo tanto, superar posicionamientos etno y androcéntricos en los MDD, los cuales se derivan de alguna manera de una concepción científica también marcada por esa misma perspectiva (Sánchez Bello, 2002). A este respecto, Rebollo et al. (2009) plantean la necesidad de diseñar los materiales y recursos tecnológicos desde la perspectiva de los derechos humanos y la equidad, con clara referencia a la creación y uso de los mismos desde la visión y el conocimiento femeninos y evitando sesgos $y$ estereotipos que muchas veces existen -en ocasiones de forma muy sutil- en los recursos tecnológicos. Podemos ampliar esta misma reflexión en relación a las personas pertenecientes a los colectivos analizados todos ellos en su mayoría invisibilizados-, por lo que sigue siendo necesario presentar en los materiales, realidades no hegemónicas y tendentes a restablecer representatividades y protagonismos, reconociéndonos como sociedad diversa y considerando dicha diversidad como un valor en sí mismo sujeto a la promoción de la justicia social y la equidad en todas sus dimensiones.

\section{Bibliografía}

Area, M., Cepeda, O., González, D. y Sanabria, A. (2010) 'Un análisis de las actividades didácticas con TIC en aulas de educación secundaria', Pixel-Bit. Revista de Medios y Educación, 38, pp. 187-199.

Area Moreira, M. (2016) 'La escuela de la sociedad digital: análisis y propuestas para la producción y uso de los contenidos digitales educativos', Escuel@ digit@। [Edu2015-64593-R]. Resumen de la memoria técnica del proyecto (Documento oficial, difusión restringida). Tenerife: Universidad de la Laguna.

Beckett, A., Ellison, N., Barrett, S. y Shah, S. (2010) 'Away with the fairies? Disability within primary-age children's literature', Disability \& Society, 25(3), pp. 373-386, https://doi.org/10.1080/09687591003701355

Berkowitz, D., Manohar,N.N. y Tinkler,J.E. (2010) 'Walk like a man, talk like a woman: Teaching the social construction of gender. Teaching Sociology, 38(2), pp.

$132-143$. https://doi.org/10.1177/0092055X10364015

Biemmi, I. (2015) 'The imagery of gender in Italian textbooks. Research into primary school books', Foro de Educación, 13(18), pp. 15-35. https://doi.org/10.14516/fde.2015.013.018.000

Cabrera García-Ochoa, Y. y Martínez-Bello, V. (2014) Libros para niñas y libros para niños: presencia de estereotipos de género en una colección de libros para dibujar. Cuestiones de género: de la igualdad y la diferencia, 9, pp. 184-217.

Castro-Rodríguez, M.M., De Castro Calvo, A. y Hernández Rivero, V. (2017) 'Análisis de plataformas educativas digitales comerciales españolas destinadas a Educación Primaria', Revista Latinoamericana de Tecnología Educativa, 16(2), pp. 49-62. http://dx.medra.org/10.17398/1695-288X.16.2.49

Cepeda Romero, O., Gallardo Fernández, I.M. y Rodríguez Rodríguez, J. (2017) ‘La evaluación de los materiales 
Rego-Agraso, Laura; Barreira Cerqueiras, Eva María y Mariño Fernández, Raquel (2018) "La representación de la diversidad social en los materiales didácticos digitales". @tic revista d'innovació educativa, 20, 63-71.

didácticos digitales', Revista Latinoamericana de Tecnología Educativa, 16(2), 79-95. http://dx.medra.org/10.17398/1695-288X.16.2.79

Consejo Escolar de Canarias (2001) 'Multiculturalidad en los Centros Escolares de Canarias. Documento de Sintesis', La Laguna- Tenerife: Gobierno de Canarias. Recuperado de http://ir.uv.es/uc251iV

García Perales, R. (2012) 'La educación desde la perspectiva de género', Ensayos Revista de la Facultad de Educación de Albacete, 27, pp. 1-18.

Gómez Carrasco, C. J. y Tenza Vicente, S. (2015) 'Un género invisible. Análisis de la presencia de las mujeres en los libros de textos de Historia de $4^{\circ}$ de la ESO', en A. M. Hernández Carretero (coord.). Una enseñanza de las ciencias sociales para el futuro: Recursos para trabajar la invisibilidad de personas, lugares y temáticas, pp. 781-791. Cáceres: Universidad de Extremadura.

González Pascual, M. (2005) ‘¿Tienen sexo los contenidos de la Educación Física Escolar? Transmisión de estereotipos de sexo a través de los libros de texto en la etapa de Secundaria', Revista Internacional de Medicina y Ciencias de la Actividad Física y el Deporte, 5(18), pp. 77-88.

González-Palomares, A. y Rey-Cao, A. (2013), 'Cultura corporal y estereotipos en las imágenes de libros de texto de educación física publicados bajo el periodo de la ley orgánica de educación (LOE)', Ágora para la EF y el deporte, 15(1), pp. 1-19.

Hall, M. (2014) 'Gender Representation in Current EFL Textbooks in Iranian Secondary Schools', Journal of Language Teaching and Research, 5(2), pp. 253261. https://doi.org/10.4304/jttr.5.2.253-261

Lee, J.F.K. (2014) 'A hidden curriculum in Japanese EFL textbooks: Gender representation', Linguistics and Education, 27, pp. 39-53. https://doi.org/10.1016/j.linged.2014.07.002

López-Navajas, A. (2014) 'Análisis de la ausencia de las mujeres en los manuales de la ESO: una genealogía de conocimiento ocultada', Revista de Educación, 363, pp. 282-308.

Macgillivray, I.K. y Jennings, T. (2008) 'A Content Analysis Exploring Lesbian, Gay, Bisexual, and Transgender Topics in Foundations of Education Textbooks', Journal of Teacher Education, 59, pp. 170-188. https://doi.org/10.1177/0022487107313160

Martínez-Bello, V. (2013) 'Representación racial, diversidad corporal y género en las imágenes de libros de texto españoles de educación infantil', Diálogos sobre educación, 7, pp. 1-17.

Martínez-Bello, V. y Martínez-Bello, D. (2016) ‘Depictions of Human Bodies in the Illustrations of Early Childhood Textbooks', Early Childhood Education Journal, 44, pp. 181-190. https://doi.org/10.1007/s10643-015-0701-x

Menescardi Royuela, C., Estevan Torres, I., Ros Ros, C. y Moya-Mata, I. (2017) 'Estereotipos corporales en las imágenes de los libros de texto de inglés', Educatio Siglo $\quad X X I, \quad 35(1), \quad$ 55-76. https://doi.org/10.6018/j/286221

Mineshima, M. (2008) 'Gender representation in an EFL textbook', Bulletin of Nigata Institute of Technology, 13, pp. 121-140. Recuperado de: http://www.niit.ac.jp/lib/contents/kiyo/genko/13/14 MINESHIMA.pdf

Moreno, O. (2006) 'Estudio Profesores LGTB: Invisibilidad, falta de formación y escasez de materiales', en: Colectivo de Lesbianas, Gais, Transexuales y Bisexuales de Madrid (COGAM) y Federación Estatal De Lesbianas, Gais, Transexuales y Bisexuales (FELGT). Homofobia en el sistema educativo. Recuperado de: http://ir.uv.es/A4VdxUF

Moya-Mata, I., Ros, C., Menescardi, C. y Bastida, A. (2013) 'Las imágenes de los libros de texto de educación física en la etapa de primaria desde la perspectiva de género', Revista Tándem, 41, pp. 4148.

Moya-Mata, I., Ruiz Sanchis, L., Ruiz, J.M., Pérez AlonsoGeta, P.M. y Ros Ros, C. (2017) 'La representación de la discapacidad en las imágenes de los libros de texto de Educación. Física: ¿inclusión o exclusión?', Retos. Nuevas Tendencias en Educación Física, Deporte y Recreación, 32, pp. 88-95.

Potgieter, C. y Reygan, F.C.G. (2012) 'Lesbian, gay and bisexual citizenship: A case study as represented in a sample of South African Life Orientation textbooks', Perspectives in Education, 30(4), pp. 39-51.

Puentes, J. y Gougherty, M. (2011) Intersections of Gender, Race, and Class in Introductory Textbooks, Teaching Sociology, 41(2), pp. 159-171. https://doi.org/10.1177/0092055X12455527

Rebollo, García, Vega, Buzón y Barragán (2009) ‘Género y TIC en Educación Superior: recursos virtuales no sexistas para el aprendizaje', Cultura y Educación, 21(3), 257-274. https://doi.org/10.1174/113564009789052316

Rey-Cao, A., Táboas-Pais, M.I. y Canales Lacruz, I. (2013) 'La representación de las personas mayores en los libros de texto de Educación Física', Revista de Educación, 362, extraordinario, pp. 129-153.

Sánchez Bello, A. (2002) 'El androcentrismo científico: el obstáculo para la igualdad de género en la escuela', Educar, 29, pp. 91-102. https://doi.org/10.5565/rev/educar.331

Sleeter, C. E. y Grant, C. A. (2011) 'Race, class, gender and disability in current textbooks', en E.F. Provenzo, A.N. Shaver y M.Bello (Eds.). The textbook as discourse. Sociocultural dimensions of American schoolbooks, pp.183-215. New York: Routledge

Soler-Castillo, S. (2008) 'Pensar la relación análisis crítico del discurso y educación. El caso de la representación de indígenas y afrodescendientes en los manuales escolares de ciencias sociales en Colombia', Discurso \& Sociedad, 2(3), pp. 642-678.

Soler-Quílez, G. (2015) 'La representación de la diversidad afectivo-sexual en el cómic. Algunos materiales para trabajar en el aula', En N. Ibarra Rius, J. Ballester Roca, M.L. Carrió Pastor y F. Romero Forteza (Eds.). Retos en la adquisición de las literaturas y de las lenguas en la era digital, pp. 569572. Valencia: Universitat Politécnica de Valencia.

Soler-Quílez, G. (2016) 'Una mirada sobre el arcoíris: la 
Rego-Agraso, Laura; Barreira Cerqueiras, Eva María y Mariño Fernández, Raquel (2018) "La representación de la diversidad social en los materiales didácticos digitales”. @tic revista d'innovació educativa, 20, 63-71.

representación de la diversidad afectivo-sexual en el álbum ilustrado', en A. Díez Mediavilla, V. Brotons y Rico, D. Escandell Maestre y J. Rovira Collado (Eds.) Aprendizajes plurilingües y literarios. Nuevos enfoques didácticos, pp. 769-765. Alacant: Universitat d'Alacant.

Táboas-Pais, M. I. y Rey-Cao, A. (2012) 'Disability in Physical Education Textbooks: An Analysis of Image Content', Adapted Physical Activity Quarterly, 29, pp. 310-328. https://doi.org/10.1123/apaq.29.4.310

Tofiño, I. (2006) ‘¿Un libro homófobo? ¡Que lo lea Rita! Criterios de valoración con referente pedagógico para los materiales LGBT destinados a menores', Educación y Biblioteca, 152, pp. 83-88.

Torres Santomé, J. (2008) 'Diversidad cultural y contenidos escolares', Revista de Educación, 345, pp. 83-110.

Vaíllo, M. (2016) 'La investigación sobre libros de texto desde la perspectiva de género: ¿hacia la renovación de los materiales didácticos?' Tendencias Pedagógicas, 27, pp. 97-124. https://doi.org/10.15366/tp2016.27.003

Weninger, C. y Williams, J. P. (2005) 'Cultural representations of minorities in Hungarian textbooks' Pedagogy, Culture \& Society, 13(2), pp. 159-180. https://doi.org/10.1080/14681360500200222

Zapico, M. H. (2015) 'The image of aging in digital curricular materials', en J. Rodríguez, E. Bruillard y M. Horsley (eds.) Digital textbooks, what's new? , pp. 260-274. Universidade de Santiago de Compostela. Santiago de Compostela: IARTEM/Servizo De Publicacións USC.

| Cita recomendada de este artículo

Rego-Agraso, Laura; Barreira Cerqueiras, Eva María y Mariño Fernández, Raquel (2018). "La representación de la diversidad social en los materiales didácticos digitales”. @tic revista d'innovació educativa. 20, 63-71. 